\title{
Una aplicación de Realidad Aumentada para recorrer el sitio patrimonial "Aldea de San Lorenzo"
}

\author{
An application of Augmented Reality to explore the heritage site \\ "Aldea de San Lorenzo"
}

\author{
Marcelo Muñoz-Sajama ${ }^{1}$ \\ Diego Aracena-Pizarro ${ }^{1 *}$ \\ Rodrigo Cornejo-Mejías ${ }^{2} \quad$ Mónica Navarrete-Álvarez ${ }^{2}$ \\ Recibido 27 de junio de 2018, aceptado 06 de agosto de 2018 \\ Received: June 27, 2018 Accepted: August 06, 2018
}

\begin{abstract}
RESUMEN
Este trabajo muestra el desarrollo de una aplicación de Realidad Aumentada que acerca al Museo Arqueológico San Miguel de Azapa, un patrimonio cultural de difícil acceso mediante representaciones de 2D y 3D de acuerdo con la investigación histórica disponible. La aplicación para dispositivos móviles con sistema operativo Android, permite conocer la historia de una comunidad ancestral que habitaba hace mil años en la "Aldea de San Lorenzo" ubicada en el norte de Chile, a través de las interfaces de usuario propuestas en el contenido sobre el que se describen, el aspecto habitacional de los recintos hallados en el sitio patrimonial, las actividades que se realizaron en el interior de la vivienda y el proceso de almacenamiento de alimentos. El desarrollo muestra la utilización de las herramientas ARToolKit y Vuforia para Unity, que permiten trabajar con Realidad Aumentada a través de una estructura de archivos que sirven para crear escenas con interfaces interactivas y modelamiento de 3D de manera directa. La aplicación final resulta de la retroalimentación de usuarios escolares y público general, a partir de su uso en muestras interactivas y ferias tecnológicas. Se espera que el desarrollo de esta aplicación pueda contribuir a acercar los lugares culturales de difícil acceso a cualquier persona y aportar con ello a la valoración del patrimonio local.
\end{abstract}

Palabras clave: Realidad aumentada, Vuforia, Unity, Aldea de San Lorenzo, arqueología, educación activa.

\begin{abstract}
This paper shows the development of an Augmented Reality application that brings the Archaeological Museum of San Miguel de Azapa, a cultural heritage of difficult access through $2 D$ and $3 D$ representations according to the available historical research. The application for mobile devices with Android operating system allows knowing the history of an ancestral community that lived a thousand years ago in the "Aldea de San Lorenzo" located in the north of Chile. Through the user interfaces proposed in the content about which they are described, the housing aspect of the enclosures found in the heritage site, the activities that were carried out inside the housing and the food storage process. The development shows the use of the tools ARToolKit and Vuforia for Unity that allow working with Augmented Reality through a file structure, which is used to create scenes with interactive interfaces and $3 D$ modeling directly. The final application results from the feedback of school users and the general public, from its use in interactive samples and technology fairs. It is hoped that the development of this application can contribute to bring the cultural places of difficult access to anyone and contribute thereby to the valuation of the local heritage.
\end{abstract}

Keywords: Augmented reality, Vuforia, Unity, Aldea de San Lorenzo, archaeology, education active.

1 Escuela Universitaria de Ingeniería Industrial, Informática y Sistemas, Área de Ingeniería de Computación e Informática. Universidad de Tarapacá. Arica, Chile. E-mail: marcelomunozsajama@gmail.com, daracena@academicos.uta.cl

2 Programa Asociativo Regional Explora de CONICYT de la Región de Arica y Parinacota. Universidad de Tarapacá. Arica, Chile. E-mail: rodrigocornejomejias@gmail.com,monica.navarrete@gmail.com

* Autor de correspondencia 


\section{INTRODUCCIÓN}

La XV Región de Arica y Parinacota tiene diversos lugares y construcciones que contienen sucesos históricos llamados patrimonios culturales [1] con los cuales se ha provisto reconstruir y mantener viva la cultura regional entre generaciones. El trabajo de arqueólogos e historiadores con elementos hallados en la zona ha permitido interpretar el hábitat, estilo de vida, herramientas de construcción, tipo de trabajo, tipo de alimentación, organización política, creencias, vestimentas y el tipo de vivienda, entre otros. Hallazgos que han sido traspasados a un registro de documentos, mientras que la materialidad descubierta se encuentra contenida en cubículos de exposición en el Museo Arqueológico San Miguel de Azapa (MASMA). Otros elementos materiales asociados a la habitabilidad y organización territorial, se pueden observar en los sitios patrimoniales, característica que concita el interés en la población local, turistas e investigadores.

Uno de ellos es la Aldea de San Lorenzo ubicado en la ribera sur del rio San Miguel de Azapa sobre una loma a los pies de la cadena de cerros que circunda el valle en la XV Región. Este asentamiento, es uno de los sitios arqueológicos más representativos del periodo Intermedio tardío y Tardío (años 11001400 d. C.) y se caracteriza por presentar un estado de conservación de los materiales vinculados a las actividades realizadas en él [2, 3]. El sitio permite apreciar dos ocupaciones de gran valor arqueológico: un gran sector destinado a la habitabilidad o vivienda ubicado en las coordenadas 19k 374.993E 7951.560N y otro destinado a actividades funerarias ubicado en el sector suroeste a $400 \mathrm{~m}$ del asentamiento habitacional [3]. Asimismo, por lo descrito en Muñoz Ovalle [4] ha permitido observar y entender el sistema de vida, las actividades en el interior de los recintos habitacionales, el sistema constructivo y las relaciones espaciales entre los asentamientos. Sin embargo, esta gran riqueza cultural está limitada en su acceso por la dificultad de conectividad vial y ubicación geográfica con lo cual no todos pueden acceder a él.

Este trabajo utiliza la disponibilidad de herramientas tecnológicas de bajo costo para acercar el sitio patrimonial Aldea de San Lorenzo a todo público, en especial a las personas con movilidad reducida que asiste a MASMA, mediante su reconstrucción por medio de la Realidad Aumentada (RA).
Una aplicación de RA instalada en los dispositivos móviles con sistema operativo Android, permite al usuario enfocar la cámara a un plano representativo del patrimonio cultural, para recorrer el sitio mediante representaciones de 2D y 3D. La visita virtual con imágenes de referencia, le da acceso a información arqueológica e histórica de estos asentamientos y a los elementos materiales relacionados con el hábitat cultural de la población ancestral.

La RA ha sido utilizada en otros museos y sitios arqueológicos como herramienta novedosa y muy atractiva para acercar a las generaciones nuevas a los espacios culturales. El Museo de Louvre en Francia [5] es uno de ellos. El trabajo de Caro Martínez, Hernando Hernández y Jiménez Díaz [6], muestra una aplicación de RA en el Museo de América de Madrid desarrollada con las herramientas, Vuforia y Unity, para dar vida a los personajes sobre un mapa mudo que proporciona información sobre las culturas existentes. Otro ejemplo de aplicación de RA se presenta en Chatzidimitris, Kavakli, Economou y Gavalas [7] llamado ARmuseum como una guía interactiva diseñada para niños de entre diez y doce años. El juego tiene lugar en el Museo de Producción de Aceite de Oliva Industrial en Lesbos, Grecia. Utilizando las dependencias del antiguo molino de aceite comunal, la aplicación invita al estudiante a completar una serie de tareas de acuerdo con las etapas involucradas en el proceso de la elaboración del aceite de oliva.

Mediante la RA, en MASMA se dispone de una guía automatizada que reconoce los objetos mostrados de la vitrina en 2D. El módulo de Tracking inserto en este sistema, utiliza el algoritmo SIFT y los cálculos matemáticos para realizar Homografía [8]. Otra aplicación informática, disponible en MASMA, viene descrita en el trabajo de Aracena Pizarro, Paredes Orellana y Córdova-González [9] que muestra el desarrollo de una plataforma tecnológica que utiliza un rompecabezas para transmitir lúdicamente a los estudiantes, información sobre los tejidos precolombinos. La interfaz gráfica del juego permite su uso interactivo mediante videos explicativos que van incrementando el nivel de juego.

Estas aplicaciones han sido utilizadas particularmente como elementos de apoyo en las salidas pedagógicas a MASMA por parte de la población escolar. Hecho que lleva al programa de valoración y divulgación 
Explora de la Comisión Nacional de Ciencia y Tecnología de Chile (CONICYT), sede Arica y Parinacota; a levantar la aplicación de RA del sitio incorporando este patrimonio cultural a MASMA como elemento de apoyo para los programas de inclusión educativa destinado a estudiantes con movilidad reducida y/o visual particularmente.

En los párrafos siguientes, se muestra el desarrollo de la aplicación y la evaluación obtenida como herramienta educativa para usuarios que participaron de la investigación de prueba.

\section{REALIDAD AUMENTADA}

El término Realidad Aumentada (RA) se define como la tecnología que permite mezclar el mundo real con objetos virtuales, mostrado a través de la pantalla de un dispositivo tecnológico. El origen de RA se experimentó con monitores see-through como el HMD (Head-Mounted Display), hasta llegar a los dispositivos móviles actuales como elemento de apoyo en la proyección de realidades extendidas. Lo proyectado en RA va de una escala que considera desde real a lo virtual y que contiene en alguna parte dentro del rango, todas las variaciones posibles de realidades aumentadas, virtuales, etc.

Milgram, Takemura, Utsumi y Kishino [10], presentan ejemplos de un modelado como parte del continuo realidad-virtualidad llamado Realidad Mixta, que puede percibir la vista del usuario. Esquemáticamente, la realidad mixta sigue el esquema de la Figura 1.

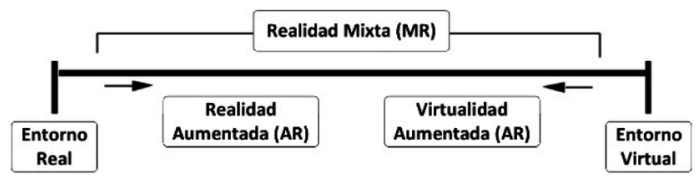

Figura 1. Representación simplificada de un continuo RV. Fuente: [10].

En cuanto al proceso empleado para su funcionamiento, se debe realizar cálculos matemáticos con variables de coordenadas de los sistemas correspondientes.

En la Figura 2 presente en Kato y Billinghurst [11], se muestra la relación entre las coordenadas del marcador y las coordenadas estimadas de la cámara mediante la detección de puntos característicos, la cual se empleó para desarrollar la herramienta ARToolKit. También se introduce en esta relación la matriz de transformación que permite convertir de un plano 3D al 2D. Este mecanismo ha permitido formar la base de nuevas herramientas, tales como, Vuforia y Wikitude para desarrollar sistemas o aplicaciones sobre las necesidades de los usuarios.

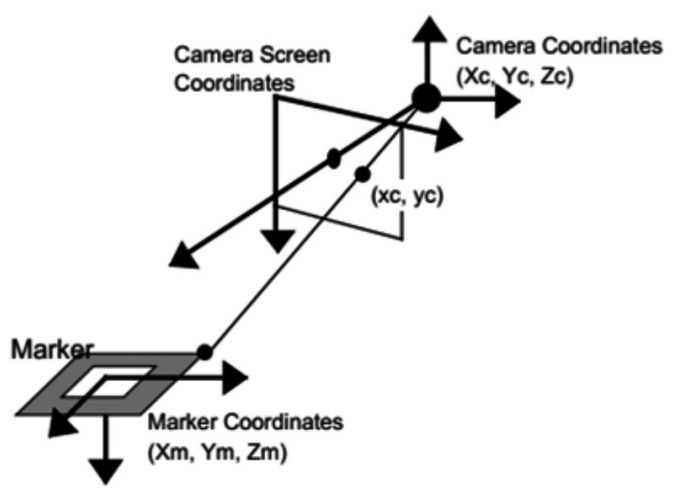

Figura 2. Relación entre las coordenadas del marcador y las coordenadas estimadas de la cámara. Fuente: [11].

\section{ARQUITECTURA DEL SISTEMA}

La arquitectura propuesta para mostrar la Aldea de San Lorenzo a través de la tecnología de Realidad Aumentada, se presenta en la Figura 3 empleando el estilo arquitectónico basado en capas.

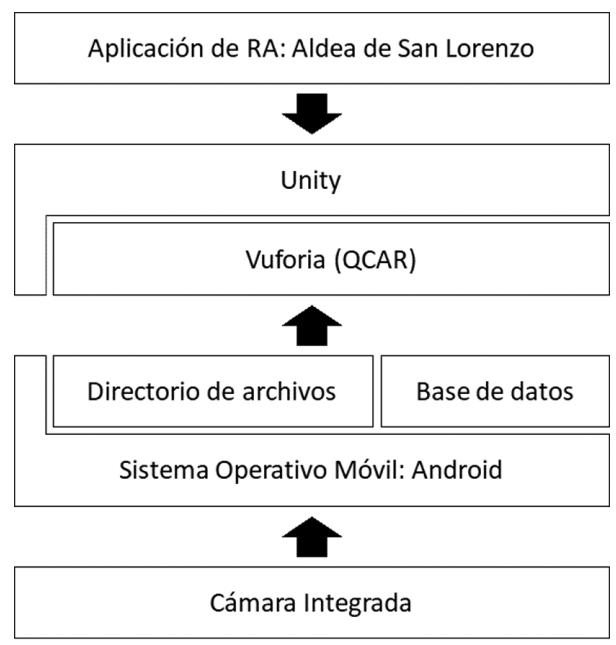

Figura 3. Arquitectura del sistema. Elaboración propia. 
Cada capa presenta las siguientes especificaciones:

- La capa de presentación contiene las interfaces de usuario o ventanas de información, permitiendo al usuario acceder a la historia del patrimonio.

- La capa de lógica de negocio está encargada de integrar el motor de Unity y las características de Vuforia para ejecutar los procesos necesarios como el llamado a funciones de los scripts C\#.

- La capa de datos suministra el almacenamiento local de datos provenientes de Unity, tales como, escenas, objetos y componentes (representaciones de 2D y 3D), y por el lado de Vuforia, los Image Targets de los recintos disponibles.

- La capa de cámara integrada del dispositivo móvil, se encarga de la entrada y salida de la escena de RA.

El funcionamiento de la aplicación comienza, cuando la cámara integrada busca un marcador (de formato impreso) ubicado en el entorno real. A continuación, en la Figura 4 se muestran los marcadores que son parte del plano territorial Az-11 de la Aldea de San Lorenzo, levantado a partir del estudio topográfico y posterior digitalización.

Una vez enfocado en el área donde se encuentra el marcador, se calcula el parámetro de posición

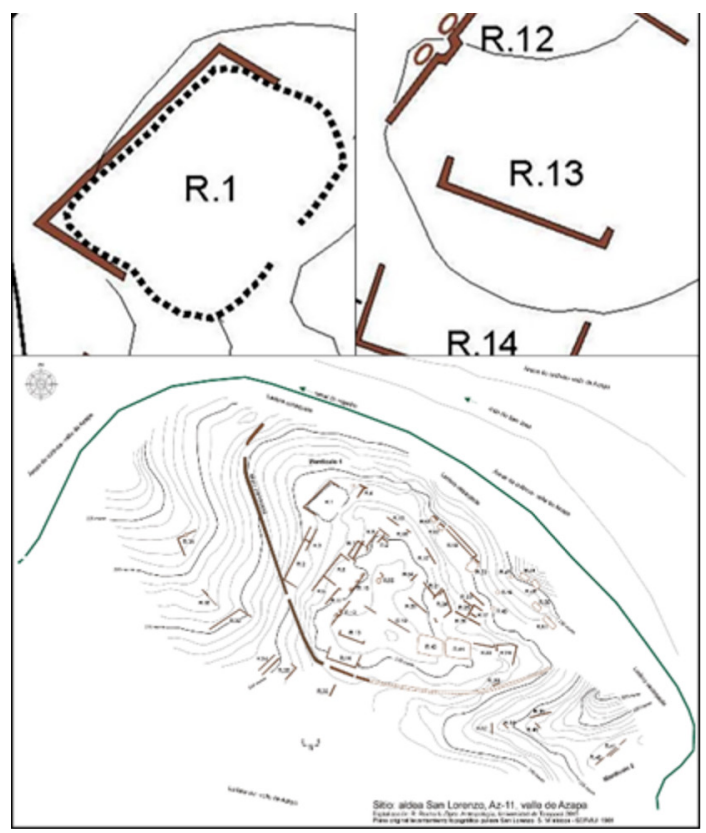

Figura 4. Marcadores de los recintos R1 y R13 en el plano territorial Az-11. Fuente: Institución de Antropología y Arqueología, UTA. y orientación mediante el sistema de coordenadas 3D. Posteriormente, se realiza la identificación del marcador en la base de datos de la aplicación, para así calcular la correspondencia de puntos entre este y su objetivo de imagen equivalente (Image Target). Si la correspondencia es exitosa, se cargan las representaciones de 3D asociadas al marcador por medio del identificador definido del Image Target. A estas representaciones se les atribuyen las coordenadas de posición y orientación del plano 2D de la pantalla táctil, las que fueron calculadas usando la transformación geométrica por Homografía. Finalmente se realiza la renderización gráfica en la escena de Realidad Aumentada mostrando objetos virtuales sobrepuestos al marcador para la vista del usuario.

En la Figura 5, se muestra el diagrama del sistema a nivel de flujo que puede optar el usuario en su dispositivo móvil, para ver el contenido de la aplicación. Las condiciones incluidas en las fases de actividades permiten la interacción secuencial usuario-sistema.

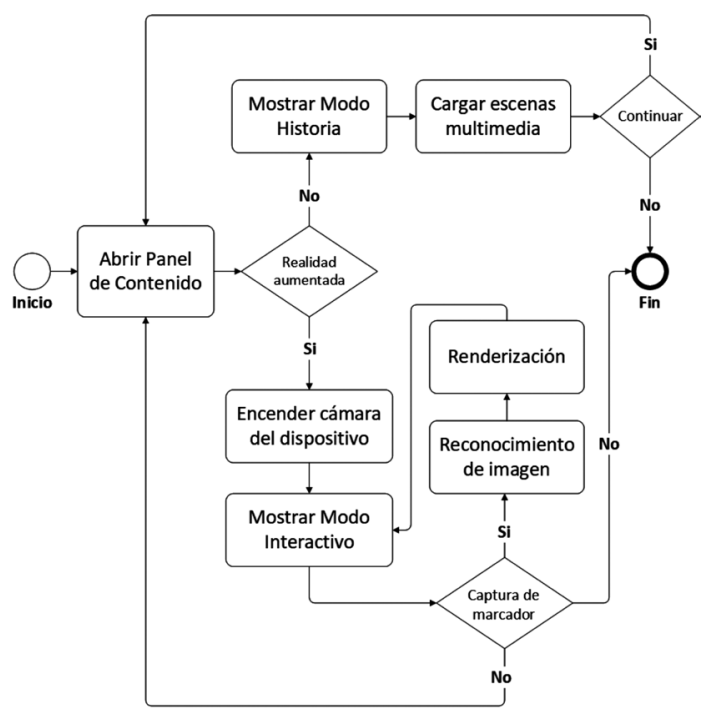

Figura 5. Flujo de trabajo. Elaboración propia.

En la representación del sitio patrimonial, se desarrollaron dos modos para mostrar la información sobre la comunidad ancestral, el Modo Historia, en donde se cargan las representaciones de 2D, tales como, ventanas, botones e imágenes y, el Modo Interactivo, modo con el que se realiza el 
seguimiento o rastreo, reconocimiento de imagen y renderización gráfica para activar la tecnología de Realidad Aumentada en 3D. Cabe señalar que ambos modos se complementan entre sí. El primero está centrado en mostrar la información usando términos científicos y el segundo entrega una visualización realista e interactiva de dicha información.

\section{Modo Historia}

La información sobre la Aldea de San Lorenzo fue dividida en seis categorías propuestas de acuerdo con el análisis arqueológico realizado. Cada categoría entrega una interfaz gráfica que contiene descripciones, galerías y botones interactivos. La Tabla 1 muestra la descripción de dichas categorías.

En la Figura 6, se muestra la composición de la escena Modo Historia, es decir, la ramificación de las escenas correspondientes a las categorías y éstas, a su vez, expanden escenas de contenido específico. Para acceder a una de estas escenas o visualizaciones se deben oprimir el botón indicado que activará la función agregada CargarEscena (), con parámetro igual al nombre de la escena solicitada.

La Figura 7 se muestra la composición visual de una galería de dispositivas presente en alguna de
Tabla 1. Información del Modo Historia.

\begin{tabular}{|c|l|}
\hline \multicolumn{2}{|c|}{ Categoría } \\
\hline Nombre & \multicolumn{1}{c|}{ Descripción } \\
\hline Reseña & $\begin{array}{l}\text { Breve resumen sobre la comunidad } \\
\text { de la Aldea de San Lorenzo. }\end{array}$ \\
\hline Investigación & $\begin{array}{l}\text { Mención del trabajo realizado por los } \\
\text { especialistas. }\end{array}$ \\
\hline Ubicación & $\begin{array}{l}\text { Indicaciones de rutas para llegar al } \\
\text { sitio patrimonial. }\end{array}$ \\
\hline Arquitectura & $\begin{array}{l}\text { Explicación del asentamiento de los } \\
\text { recintos excavados. }\end{array}$ \\
\hline $\begin{array}{l}\text { Descripción } \\
\text { Recinto 1 }\end{array}$ & $\begin{array}{l}\text { Explicación de los artefactos, la distri- } \\
\text { bución y actividades en el interior de } \\
\text { la vivienda. }\end{array}$ \\
\hline $\begin{array}{l}\text { Descripción } \\
\text { Recinto 13 }\end{array}$ & $\begin{array}{l}\text { Explicación de los artefactos, la } \\
\text { distribución y actividades en el interior } \\
\text { de la vivienda. }\end{array}$ \\
\hline
\end{tabular}

Elaboración propia.

estas escenas. Para conocer la información de cada dispositiva, se han añadido las funciones DiapositivaAnterior () y DiapositivaSiguiente () a los botones interactivos denominados BotonAnterior y BotonSiguiente, respectivamente. Estas y otras funciones están escritas en lenguaje C\#.

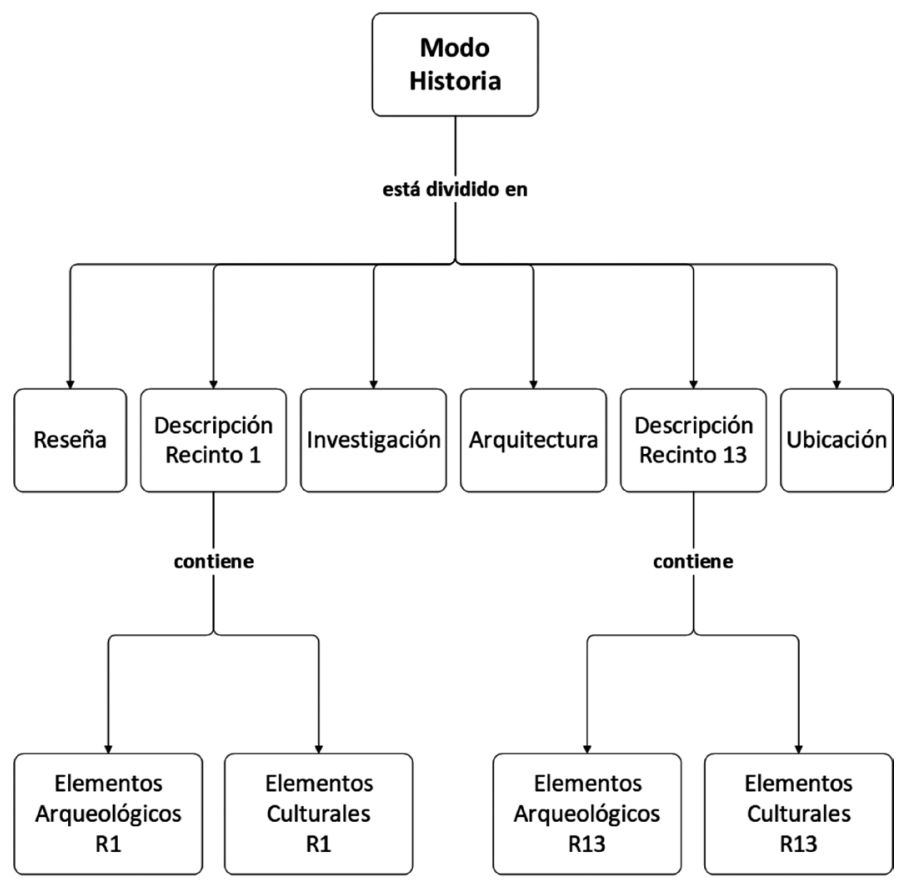

Figura 6. Ramificación de escenas del Modo Historia. Elaboración propia. 


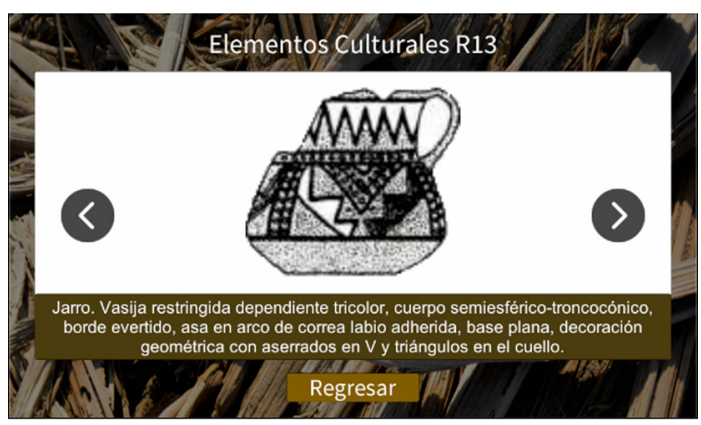

Figura 7. Galeria de diapositivas de una escena. Elaboración propia.

\section{Modo Interactivo}

Cuando el modo interactivo es seleccionado, se empieza a cargar la ejecución de la cámara integrada (tiempo de espera es igual a 30 segundos aproximadamente, dependiendo del rendimiento del dispositivo que se esté usando). Posteriormente, la escena de Realidad Aumentada es mostrada por pantalla. La Figura 8 muestra la interacción de los objetos involucrados en este modo. Mediante el envío y recepción de datos, la secuencia propuesta permite mostrar objetos virtuales sobrepuestos en el entorno real a partir del reconocimiento de marcadores de los recintos por medio del enfoque de cámara. En esta interacción, se utilizan dos gestores que colaboran entre sí; el Gestor de Vuforia, encargado de realizar el mecanismo sobre la Realidad Aumentada en el dispositivo móvil y Gestor de Unity, encargado de suministrar los recursos disponibles, tales como, las grabaciones de audio y las representaciones de 3D.

Desde el inicio de la carga de la escena de Realidad Aumentada hasta la salida de ésta, se ejecuta el mecanismo que entrega la herramienta Vuforia. Mecanismo que se presenta en la Figura 9, donde se focaliza el flujo que realiza el paquete de Realidad Aumentada para sobreponer objetos virtuales en el entorno real. Primero, se inicia los parámetros de calibración de cámara ajustada al dispositivo móvil. Enseguida, se carga la base de datos que contiene los Image Targets. Una vez encendida la cámara, se realiza la detección y rastreo de los marcadores (de formato impreso) ubicados en el entorno real, por medio del enfoque realizado por el usuario. El ciclo de la función QCAR_onUpdate (State) es llamada

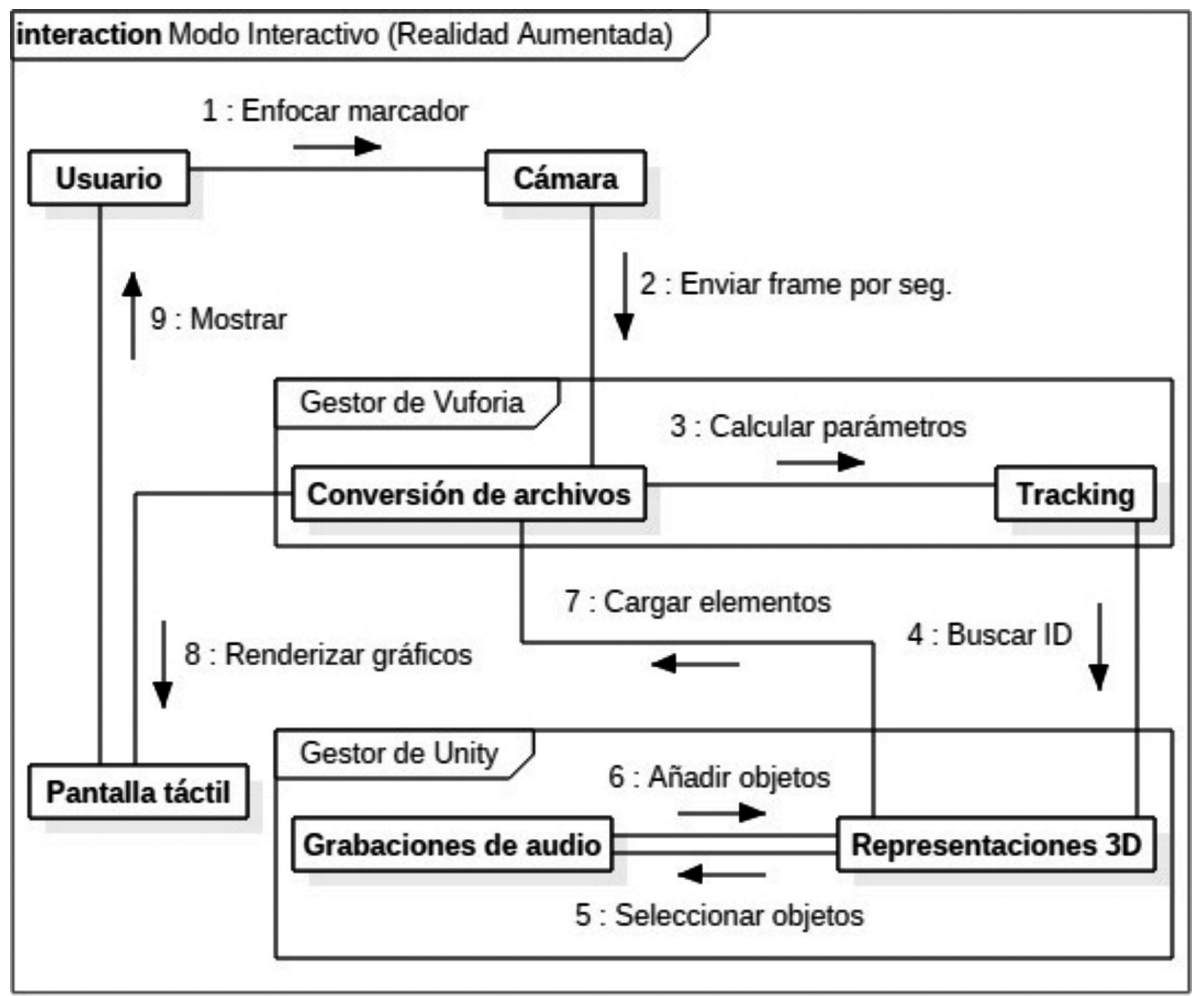

Figura 8. Diagrama de colaboración. Elaboración propia. 
cada vez que se realiza el enfoque de cámara. Si el marcador detectado coincide con su Image Target en la base de datos, las representaciones de 3D se cargarán y se mostrarán en la pantalla. En caso contrario, se debe mejorar el enfoque que puede estar afectado por la luminosidad del ambiente o movimientos de la mano, y una vez solucionado esto, se podrá realizar una exitosa correspondencia de puntos.

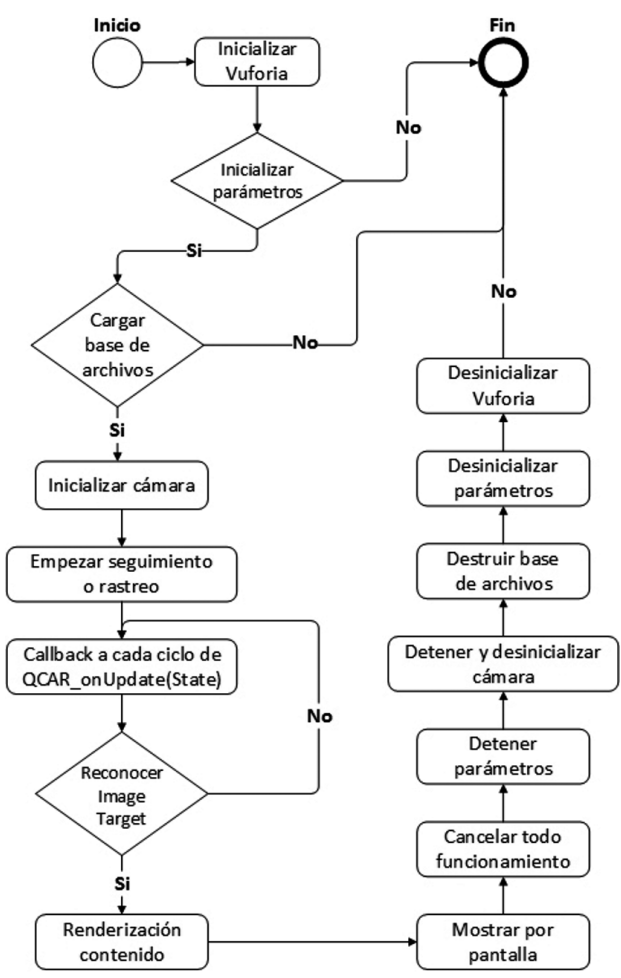

Figura 9. Mecanismo de Vuforia en el Modo Interactivo. Elaboración propia.
Para retroceder una escena o salir de la aplicación, se ejecuta la tarea de cancelación de la ejecución del mecanismo de Vuforia y desinicialización de los parámetros y archivos correspondientes.

\section{IMPLEMENTACIÓN RA PARA EL SITIO PATRIMONIAL "ALDEA DE SAN LORENZO"}

El proceso de ingeniería de software involucrado en el levantamiento de escenarios similares en RA descritos en [12], sirvió como una guía para tratar el tema de la Aldea de San Lorenzo.

Inicialmente se trabajó con la herramienta, ARToolKit junto con Unity, para crear aplicaciones básicas que muestren la tecnología de Realidad Aumentada. Su modo de trabajo entregó el mecanismo para estructurar los archivos necesarios para desplegar objetos virtuales por pantalla. Sin embargo, la calidad de sus procesos de calibración de cámara y conversión de imágenes cualesquiera al formato requerido afectaba la usabilidad de la aplicación. Posteriormente, se optó por trabajar con Vuforia en el proyecto, debido a que contiene mejoras en cuanto a la configuración de los procesos mencionados anteriormente.

La Figura 10 describe el proceso por el cual la aplicación de RA fue desarrollada. En la carpeta del proyecto, primero se guardó el paquete Vuforia para Unity que contiene todos los scripts de programación y archivos de configuración necesarios para activar la Realidad Aumentada, y segundo, la base de datos obtenida y descargada del sistema Target Manager (accedida a través de una cuenta de usuario en el

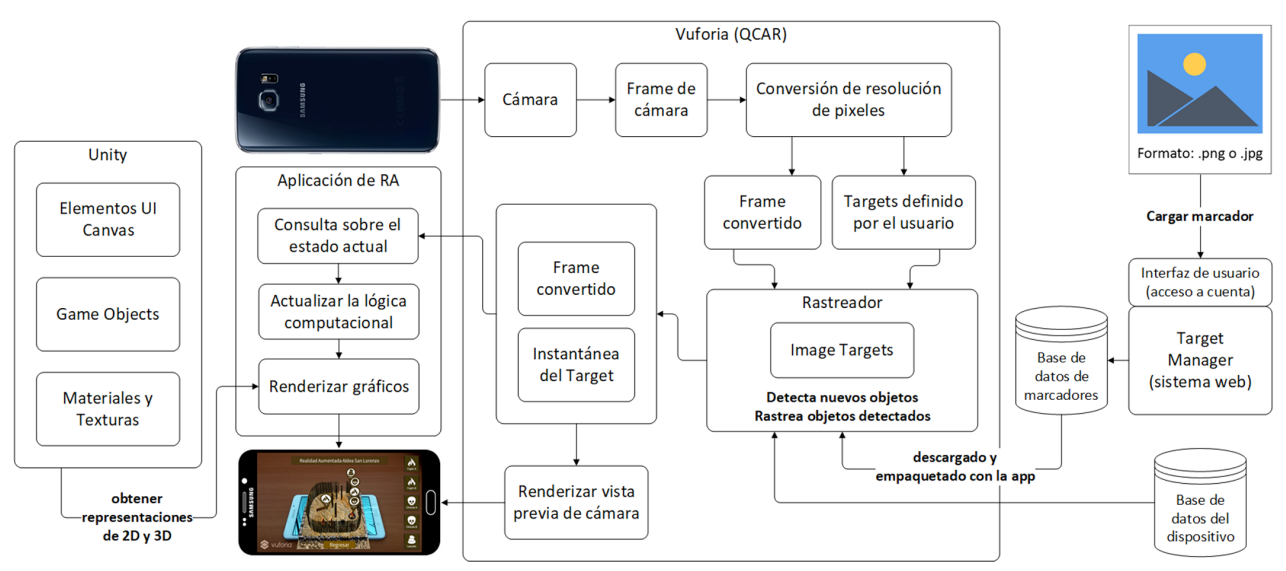

Figura 10. Proceso de desarrollo. Elaboración propia. 
sistema web) que contiene los marcadores convertidos en el formato digital requerido (Image Targets) para la aplicación mediante Vuforia. Dentro del editor gráfico Unity se importaron los dos elementos mencionados anteriormente. Luego, se crearon las escenas que recrean el sitio patrimonial. En este caso fueron dieciséis escenas sobre la Aldea de San Lorenzo, a las cuales se añadieron las representaciones de 2D y $3 \mathrm{D}$. Por ejemplo, en la escena de Realidad Aumentada se añadieron a su estructura de componentes los scripts para asociar los objetos virtuales a los marcadores. Finalmente se compiló el proyecto a un archivo APK que fue instalado en los dispositivos móviles para realizar las pruebas en los usuarios.

Con respecto a la elección de Android, se debe a la compatibilidad del sistema operativo con la aplicación, puesto que la compilación del APK necesita tener instalado Android SDK y Java JDK, los cuales están presentes en el computador (con SO Windows) usado para el desarrollo.

La Figura 11 muestra el detalle de los atributos que se modificaron en el panel Inspector para brindar funcionalidad a los componentes. Esta configuración fue realizada para agregar nuevos scripts (como ejemplo, Indicadores Elementos R1) que contengan grabaciones de audio e imágenes de los botones interactivos, y establecer los parámetros de posición, orientación y dimensiones de tamaño de los recintos.

\section{ANÁLISIS ARQUEOLÓGICO}

En Muñoz Ovalle [3], se estudió el estrato 3 que describe el aspecto habitacional de los recintos, específicamente R1 y R13. Los cuales son catalogados como viviendas. En la Figura 12 se observa la condición actual de los recintos que fueron excavados. La base de nivelación permanece casi intacta producto del material rocoso usado en ella. Aunque existen restos del entrelazado de las cañas usado para los muros de contención de las viviendas, este material ha sufrido un empeoramiento gradual por el transcurso de los años y el cambio climático. Las áreas excavadas en estos recintos, permitió estudiar la identidad de los objetos pertenecientes a los habitantes de la Aldea de San Lorenzo mediante el análisis de los restos arqueológicos.

La información se divide en dos subsecciones; los elementos arqueológicos presentes en las actividades en el interior de la vivienda, y los elementos culturales

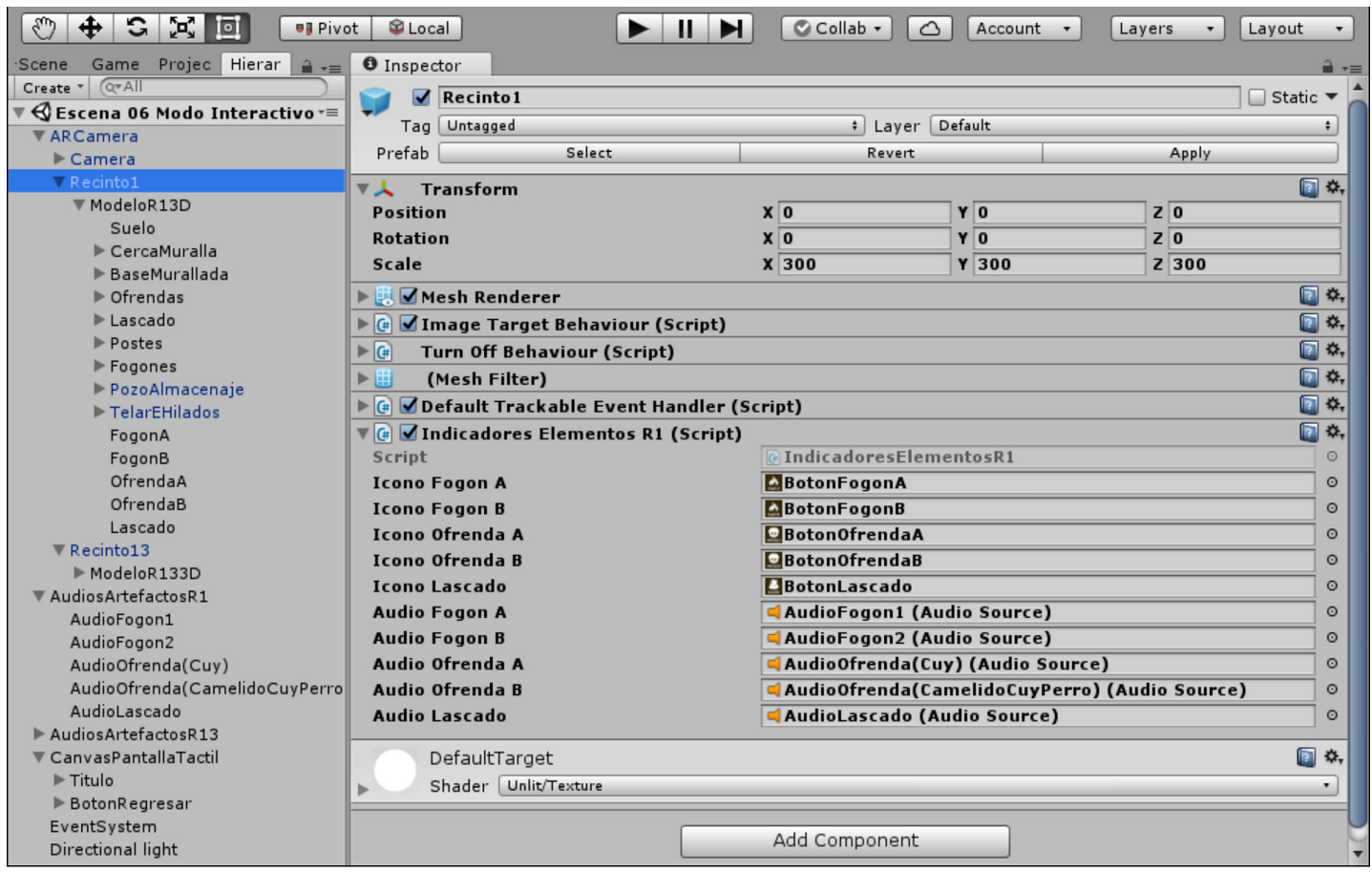

Figura 11. Panel Inspector de una escena. Elaboración propia. 


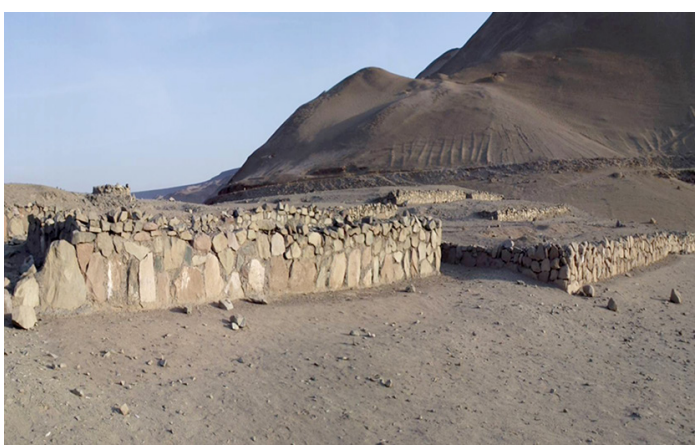

Figura 12.Estructuras habitacionales excavadas. Fuente: Institución de Antropología y Arqueología, UTA.

a partir del análisis de fragmentos de cerámica. Se han propuestos dos tablas de contenido para estructurar dicha información, las cuales se muestran a continuación.

\section{Elementos arqueológicos presentes en las actividades en el interior de la vivienda}

La Tabla 2 describe el hallazgo de elementos como los artefactos utilizados en las actividades en el interior de la vivienda. Artefactos que se asocian a cinco elementos de proyección en la aplicación. Por ejemplo, la información asociada al elemento Fogón varía entre recintos con respecto a los alimentos hallados en ellos. En cambio, el elemento que simula el Espacio de descanso mantiene la misma interpretación puesto que no hay diferencias entre una vivienda y otra. El Modo Historia, refuerza el contenido mediante el uso de textos e imágenes, mientras que el Modo Interactivo lo hace a través de grabaciones de audio pensadas en un usuario con dificultad de visión.

\section{Elementos culturales a partir del análisis de fragmentos de cerámica}

En la Tabla 3 se muestra los tipos de estilo que fueron interpretados basándose en el hallazgo de fragmentos de cerámica realizado por los expertos. El análisis se trató en la reconstrucción de elementos culturales usando los fragmentos, permitiendo así lograr la detección de figuras geométricas, colores y texturas presentes en su decoración.

\section{RESULTADOS}

La aplicación de RA sobre la Aldea de San Lorenzo, fue cargada en los dispositivos de prueba escogidos
Tabla 2. Tipos de artefactos encontrados.

\begin{tabular}{|l|l|}
\hline \multicolumn{2}{|c|}{ Elementos arqueológicos } \\
\hline \multicolumn{1}{|c|}{ Nombre } & \multicolumn{1}{c|}{ Descripción } \\
\hline Fogón & $\begin{array}{l}\text { En su interior se hallaron restos que- } \\
\text { mados de alimentos de procedencia } \\
\text { marina y cultivos de la tierra. }\end{array}$ \\
\hline Telar e hilados & $\begin{array}{l}\text { Usando las espinas de cactus y plantas, } \\
\text { tales como, el algodón y totora se } \\
\text { efectuaron confecciones de trenzado. }\end{array}$ \\
\hline $\begin{array}{l}\text { Instrumental } \\
\text { lítico }\end{array}$ & $\begin{array}{l}\text { Las rocas fueron talladas en forma } \\
\text { triangular siendo fabricadas como } \\
\text { utensilios. }\end{array}$ \\
\hline Ofrenda & $\begin{array}{l}\text { Es el significado de aspecto espiritual } \\
\text { al entierro de animales, tales como, } \\
\text { camélidos y cuyes. }\end{array}$ \\
\hline $\begin{array}{l}\text { Espacio de } \\
\text { descanso }\end{array}$ & $\begin{array}{l}\text { En Muñoz Ovalle [7] se cita lo siguiente: } \\
\text { "Esta posible área se puede deducir por } \\
\text { la presencia de postes que se distribuyen } \\
\text { en hileras, la cual atribuimos como un } \\
\text { espacio de descanso" }\end{array}$ \\
\hline
\end{tabular}

Elaboración propia.

Tabla 3. Tipos de estilo de cerámica.

\begin{tabular}{|l|l|l|}
\hline \multicolumn{3}{|c|}{ Elementos culturales } \\
\hline Nombre & \multicolumn{1}{|c|}{ Imagen } & \multicolumn{1}{c|}{ Descripción } \\
\hline $\begin{array}{l}\text { Estilo } \\
\text { San Miguel }\end{array}$ & $\begin{array}{l}\text { Cerámica engobada en } \\
\text { blanco con diseños geo- } \\
\text { métricos en rojo y negro. }\end{array}$ & $\begin{array}{l}\text { Cerámica con decoración } \\
\text { de figuras triangulares y } \\
\text { rectangulares pintadas en } \\
\text { rojo y negro sobre engobe } \\
\text { blanco. }\end{array}$ \\
\hline $\begin{array}{l}\text { Estilo } \\
\text { Las Maitas }\end{array}$ & $\begin{array}{l}\text { Cerámica con decoración } \\
\text { de hileras punteadas ver- } \\
\text { ticales en blanco. }\end{array}$ \\
\hline $\begin{array}{l}\text { Estilo } \\
\text { Chiribaya y }\end{array}$ & & \\
\hline
\end{tabular}

Elaboración propia.

para observar y registrar una experiencia interactiva en los usuarios. Experiencia probada en el smartphone Samsung Galaxy E5 y la tablet Samsung Galaxy Tab A, ambas con la versión Android 5.1.1 Lollipop. No obstante, existe la posibilidad de ser instalada en dispositivos móviles con la versión Android 4.1 Jelly Bean o superior. Además, la aplicación tiene la característica que permite ajustar el tamaño de 
objetos virtuales a cualquier resolución de pantalla sin distorsionar su diseño gráfico. Por otro lado, la calidad del enfoque de cámara en la detección y rastro de marcadores permitió inferir que mientras más pixeles tenga la resolución de la cámara integrada, se podrá sobreponer las representaciones de 3D en los marcadores de forma rápida.

En las Figuras 13 y 14 se observan el diseño de las escenas para el Modo Historia y Modo Interactivo, las cuales contienen elementos gráficos, tales como, botones e indicadores. Estos elementos permiten el usuario interactuar con la aplicación desde el dispositivo a través del modo táctil. El diseño del Modo Historia tiene como objetivo, mostrar las opciones disponibles para acceder a una información específica sobre la comunidad ancestral, y el diseño del Modo Interactivo está enfocado a crear el escenario para colocar las representaciones de 3D junto con los botones de audio que relatan la descripción de los elementos arqueológicos.

\section{Experiencia sobre el uso de la aplicación de RA}

La experiencia con los usuarios se midió de acuerdo a dos elementos. Una prueba de observación y un cuestionario, ambos levantados en las ferias tecnológicas presentes en los establecimientos educacionales de la

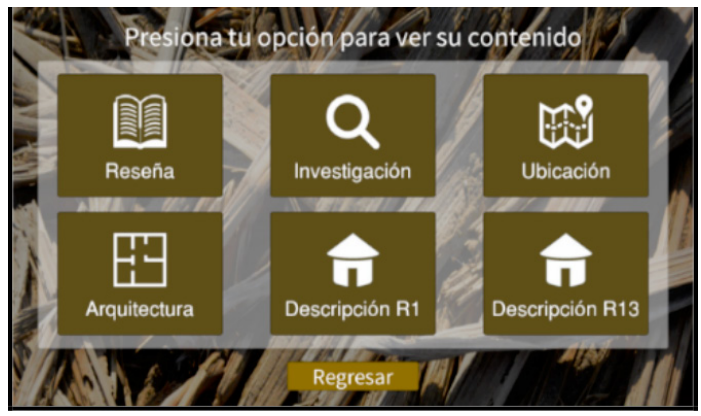

Figura 13. Modo Historia. Elaboración propia.

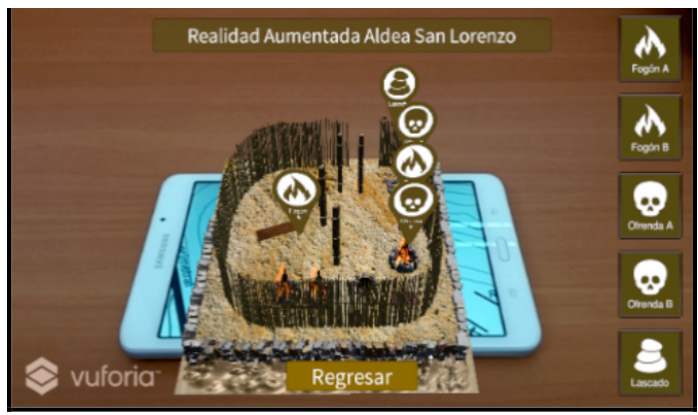

Figura 14. Modo Interactivo. Elaboración propia. ciudad de Arica y en MASMA para público general. En la Tabla 4 se muestra los datos obtenidos desde la observación y que se estimaron en relación a dos aspectos: contenido y usabilidad, manifestadas en los 71 usuarios (divididos por rango de edad) que participaron en el proceso de retroalimentación.

Para el caso de los datos cuantitativos, se realizaron tres preguntas de tipo selección múltiple relativas a: (A) Apreciación personal sobre la aplicación de RA.

(B) Composición en el diseño gráfico $2 \mathrm{D}$ y $3 \mathrm{D}$ de las escenas.

(C) Terminología de la información del patrimonio.

Cada uno de ellos medidos por la escala de evaluación; Deficiente, Aceptable y Excelente.

Las Figuras 15, 16 y 17 describen el resultado de una muestra igual a 71 usuarios que participaron en el cuestionario, los cuales fueron diferenciados según las preguntas A, B y C, respectivamente.

Respecto de esta manera, se puede observar cuáles son los aspectos que deben ser reconsiderados para

Tabla 4. Resultado de la observación estimada.

\begin{tabular}{|c|c|c|}
\hline \multicolumn{3}{|c|}{ Rangos de edad } \\
\hline Tipo & Contenido & Usabilidad \\
\hline $\begin{array}{l}\text { Estudiantes } \\
\text { (entre } 8 \text { a } \\
13 \text { años) }\end{array}$ & $\begin{array}{l}\text { Los niños de este rango } \\
\text { de edad, observaron las } \\
\text { representaciones de 3D } \\
\text { de manera divertida y } \\
\text { sorpresiva, intentando } \\
\text { capturar los objetos vir- } \\
\text { tuales con sus manos. }\end{array}$ & $\begin{array}{l}\text { Se centraron sólo en } \\
\text { manipular la escena de } \\
\text { RA. No avanzaron en el } \\
\text { uso de botones que per- } \\
\text { miten la navegación } \\
\text { sobre el resto de las es- } \\
\text { cenas disponibles en el } \\
\text { Modo Historia. }\end{array}$ \\
\hline $\begin{array}{l}\text { Estudiantes } \\
\text { (entre } 15 \text { a } \\
19 \text { años) }\end{array}$ & $\begin{array}{l}\text { Estos jóvenes mostraron } \\
\text { el interés de observar } \\
\text { los recintos en detalle. } \\
\text { Además de escuchar } \\
\text { los botones de audios } \\
\text { para conocer más sobre } \\
\text { el hallazgo de restos } \\
\text { materiales. }\end{array}$ & $\begin{array}{l}\text { Manipularon todas las } \\
\text { escenas disponibles } \\
\text { al interior de la apli- } \\
\text { cación de RA. De esta } \\
\text { manera, asociaron la } \\
\text { información del Modo } \\
\text { Historia con la del } \\
\text { Modo Interactivo. }\end{array}$ \\
\hline $\begin{array}{l}\text { Adultos } \\
\text { (35 años } \\
\text { o más) }\end{array}$ & $\begin{array}{l}\text { Este grupo de personas } \\
\text { encontró muy intere- } \\
\text { sante la aplicación pa- } \\
\text { ra ver los recintos R1 y } \\
\text { R13 por medio de re- } \\
\text { presentaciones de 3D, ya } \\
\text { que observaron el estilo de } \\
\text { vida en esa época. }\end{array}$ & $\begin{array}{l}\text { Del mismo modo que } \\
\text { los estudiantes (entre } \\
15 \text { a } 19 \text { años), vieron } \\
\text { toda la información so- } \\
\text { bre los recintos. Sin em- } \\
\text { bargo, hubo una di- } \\
\text { ficultad en manejar la } \\
\text { pantalla táctil. }\end{array}$ \\
\hline
\end{tabular}

Elaboración propia. 
Apreciación personal sobre la aplicación de RA

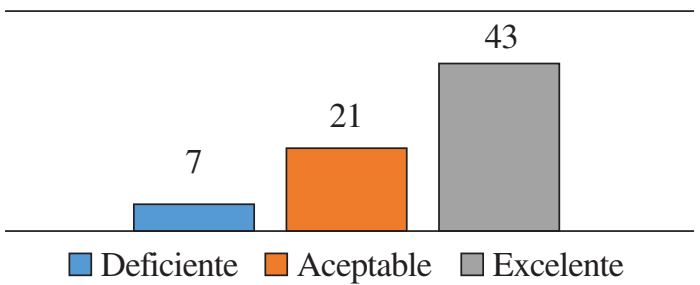

Figura 15. Resultado de la pregunta A.

Elaboración propia.

\section{Composición en el diseño \\ 2D y 3D de las escenas}

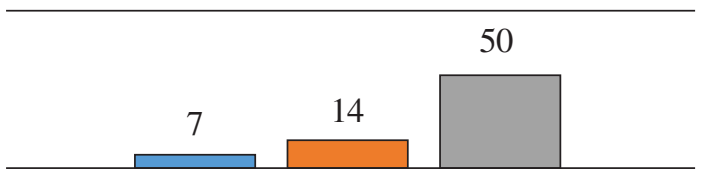

$\square$ Deficiente $\square$ Aceptable $\square$ Excelente

Figura 16. Resultado de la pregunta B.

Elaboración propia.

mejorar el contenido de la aplicación y futuras versiones. Asimismo, la interpretación de los tres gráficos que representan el resultado de cuestionario, se describe en la Tabla 5.

Cabe mencionar que el cuestionario utilizado, ha sido el método de recopilación de datos de acuerdo
Terminología de la información del patrimonio

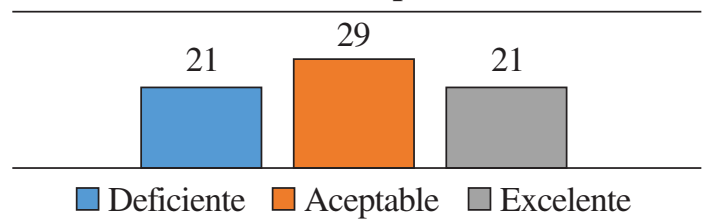

Figura 17. Resultado de la pregunta C. Elaboración propia.

a la necesidad de Explora para el trabajo realizado. Para futuras versiones, se tiene pensado capturar datos que entreguen más información y así, efectuar posibles cambios significativos en la aplicación de RA ante diferentes escenarios.

La Figura 18 muestra la manipulación del contenido de la aplicación en las personas que asistieron al evento llamado Día del Patrimonio Cultural, realizado en las dependencias del Museo Arqueológico San Miguel de Azapa.

\section{CONCLUSIONES}

La aplicación de RA al sitio patrimonial Aldea de San Lorenzo confirma el resultado obtenido en proyectos similares. La posibilidad de agregarle materialidad a la vivienda ancestral y transportar con el relato al usuario relativo al periodo intermedio tardío regional, desencadena curiosidad y atención

Tabla 5. Interpretación de los gráficos.

\begin{tabular}{|l|l|}
\hline \multicolumn{2}{|c|}{ Pregunta } \\
\hline \multicolumn{1}{|c|}{ Nombre } & \multicolumn{1}{c|}{ Descripción } \\
\hline $\begin{array}{l}\text { Apreciación } \\
\text { personal sobre la } \\
\text { aplicación de RA }\end{array}$ & $\begin{array}{l}\text { La mayor parte del total de la muestra, es decir, un 60\% de los usuarios evaluaron con Excelente, } \\
\text { e incluso, algunos evaluaron con Aceptable alcanzando a un 30\%, ya que entre ellos les pareció } \\
\text { agradable y fácil de manipular la aplicación de RA para conocer el tema de la Aldea de San Lorenzo } \\
\text { en Realidad Aumentada. Sólo el 10\% del total, evaluó con Deficiente posiblemente debido a un } \\
\text { desinterés mostrado en algunos que no navegaron por todas las escenas disponibles de la aplicación. }\end{array}$ \\
\hline $\begin{array}{l}\text { Composición en } \\
\text { el diseño gráfico } \\
\text { 2D y 3D de las } \\
\text { escenas }\end{array}$ & $\begin{array}{l}\text { El diseño de cada escena fue comprensible para el 70\% de la muestra, es decir, 50 usuarios } \\
\text { evaluaron con Excelente apuntando el uso adecuado sobre el tamaño y tipo de letra, la iconografía } \\
\text { en los botones e indicadores y la secuencia de navegación entre escenas. Sin embargo, hay un } \\
10 \% \text { que evaluaron con Deficiente ya que se manifestó una dificultad de uso entre aquellos } \\
\text { que nunca habían interactuado con este tipo de tecnología, principalmente en algunos adultos. }\end{array}$ \\
\hline $\begin{array}{l}\text { Terminología de } \\
\text { la información } \\
\text { del patrimonio }\end{array}$ & $\begin{array}{l}\text { Hay una evaluación dividida con respecto a esta pregunta referida a los términos utilizados en } \\
\text { el contenido de la aplicación que relata la historia de la comunidad ancestral. Con un 30\%, 40\% } \\
\text { y 30\%, los 71 usuarios evaluaron entre Deficiente, Aceptable y Excelente, respectivamente. } \\
\text { Algunos mostraron un conocimiento sobre aspectos culturales, mientras que, en otros se dio el } \\
\text { tiempo para explicar el significado de lo presentado por pantalla. }\end{array}$ \\
\hline
\end{tabular}

Elaboración propia. 


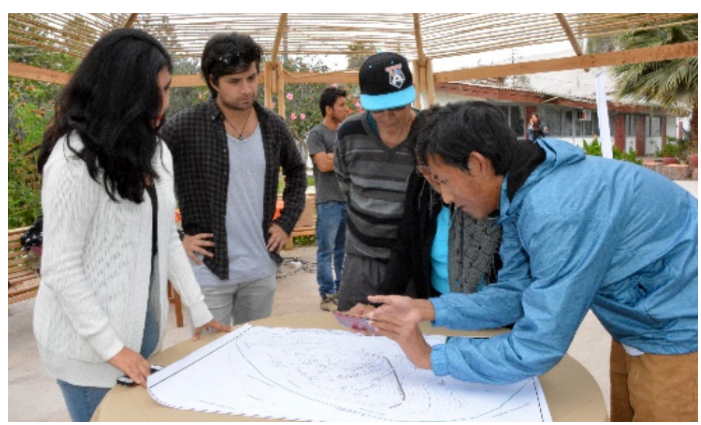

Figura 18. Exhibición en el Día del Patrimonio Cultural. Elaboración propia.

en todo tipo de público en especial aquellos que no habían conocido el sitio in situ por diferentes motivos. Las evaluaciones realizadas a la aplicación destacan una interfaz amigable y una enseñanza interactiva del patrimonio cultural regional que contribuye a lo entregado en MASMA. Sin embargo, se destaca la necesidad de orientar la aplicación de acuerdo con las características del usuario. A futuro, se considera utilizar imágenes de otros lugares que vayan mostrando más información de la Aldea de San Lorenzo.

\section{AGRADECIMIENTOS}

Se agradece la colaboración del Proyecto Asociativo Regional Explora de CONICYT de la Región de Arica y Parinacota y del Proyecto de Investigación en Educación $\mathrm{N}^{\circ}$ 8741-14 de la Universidad de Tarapacá, por brindar apoyo en la realización de este trabajo. Además, agradecer al Director del MASMA, Dr. Iván Muñoz Ovalle y sus colaboradores por su tiempo en responder nuestras inquietudes.

\section{REFERENCIAS}

[1] J. Barraza Llerena. "Manual de Patrimonio Cultural y Natural Arica Parinacota". Ministerio de Educación. FONDART Regional y Consejo de Monumentos Nacionales, 213, pp. 2003.

[2] I. Muñoz Ovalle y G. Focacci Aste. "San Lorenzo: Testimonio de una comunidad de agricultores y pescadores Postiwanaku en el valle de Azapa (Arica - Chile)". Chungara. Revista de Antropología Chilena. No 15, pp. 7-30. 1985.

[3] I. Muñoz Ovalle. "Estrategias de organización prehispánicas en Azapa: El impacto de la agricultura en un valle del desierto costero del pacifico". Ediciones Universidad de Tarapacá, 357, pp. 2004.
[4] I. Muñoz Ovalle. "Hurgando la vivienda andina a través de la historia: Percepción y ocupación del espacio doméstico-ceremonial en los valles y altiplano en la Región de Arica y Parinacota, Chile". Intersecciones en antropología. Vol. 15, No 1, pp. 235-250. ISSN 1850-373X. 2014.

[5] T. Miyashita, P. Meier, T. Tachikawa, S. Orlic, T. Eble, V. Scholz, A. Gapel, O. Gerl, S. Arnaudov, S. Lieberknecht. "An augmented reality museum guide". ISMAR "08 Proceedings. 7th IEEE/ACM International Symposium on Mixed and Augmented Reality, pp. 103-106. 2008.

[6] M. Caro Martínez, D. Hernando Hernández y G. Jiménez Díaz. "RACMA o cómo dar vida a un mapa mudo en el Museo de América". II Congreso de la Sociedad Española para las Ciencias del Videojuego. España. 2015.

[7] T. Chatzidimitris, E. Kavakli, M. Economou and D. Gavalas. "Mobile AR edutainment applications for cultural institutions". Fourth International Conference on Information, Intelligence, Systems and Applications. Greece. 2013.

[8] D. Aracena-Pizarro and J. Mamani-Castro. "Museum guide through annotations using Augmented Reality". WSCG. 18th International Conference in Central Europe on Computer Graphics, Visualization and Computer Vision, pp. 35-38. ISBN 978-8086943-95-4. 2010.

[9] Y. Paredes Orellana, D. Aracena Pizarro y J. Córdova-González. "Aprender jugando con tejidos precolombinos mediante rompecabezas virtuales". Ingeniare. Revista Chilena de Ingeniería. Vol. 16, No 2, pp. 318325. ISSN 0718-3305. 2008.

[10] P. Milgram, H. Takemura, A. Utsumi and F. Kishino. "Augmented Reality: A class of displays on the Reality-Virtuality Continuum". Proceedings of SPIE. Telemanipulator and Telepresence Technologies. Vol. 2351, pp. 282-292. 1994.

[11] H. Kato and M. Billinghurst. "Marker tracking and HMD calibration for a video-based Augmented Reality Conferencing System". IWAR '99 Proceedings. 2nd IEEE and ACM International Workshop on Augmented Reality, pp. 85-94. 1999.

[12] D. Aracena Pizarro y S. Moscoso Gallo, "ARchitect: An authoring tool to compose scenes in Augmented Reality". INFONOR. II Congreso Internacional de Ingeniería en Computación e Informática del Norte de Chile. 2011. 